\title{
Maxadilán: un potente vasodilatador cutáneo aislado de la especie Lutzomyia longipalpis, vector de la leishmaniasis visceral
}

\author{
Clara P. Ordóñez ${ }^{1}$, Ethan Lerner ${ }^{2}$
}

La leishmaniasis es una enfermedad causada por un protozoario del género Leishmania, llamada así en reconocimiento a William Leishman, investigador escocés, quien fue el primero en observar el microorganismo al microscopio a comienzos de 1900 (1). La transmisión ocurre mediante la picadura de un vector del género Lutzomyia infectado con los promastigotes de Leishmania. Las diversas manifestaciones clínicas dependen, entre otros factores, de la especie de Leishmania infectante, de la respuesta inmune del huésped y del vector.

Las diferentes formas de la enfermedad son comunes en suramérica y centroamérica, así como en el medio oriente y en la India. Se manifiesta por úlceras en la piel o por destrucción de las mucosas en la leishmaniasis cutánea y mucocutánea; mientras que en la forma visceral se afecta el bazo y el hígado, principalmente (2).

La leishmaniasis es transmitida por diferentes especies de vectores, cuando éstos inoculan promastigotes en la piel durante el proceso de obtener sangre como alimento y como estímulo para la oviposición; estos promastigotes invaden los macrófagos locales, se multiplican intracelularmente y producen su ruptura, invadiendo así otros macrófagos.

La glándulas salivales de los vectores tienen diversas sustancias que posiblemente facilitan la colonización del parásito en el nuevo huésped y producen localmente vasodilata- ción, inhibición de la agregación plaquetaria y, por tanto, inhibición de la coagulación; la inoculación de parásitos de Leishmania en presencia de homogenizados de glándulas salivales de Lutzomyia hace que las lesiones cutáneas sean de mayor tamaño y contengan gran cantidad de parásitos comparado con los controles. Es por esto que se ha postulado que las diversas sustancias contenidas en la saliva del vector podrían además modular la respuesta inmune inicial e influir en el curso de la enfermedad (3).

En Colombia, Leishmania panamensis $(53,8 \%)$ y Leishmania braziliensis $(30,3 \%)$ son la causa más común de leishmaniasis cutánea o mucosa mientras que la leishmaniasis visceral es producida por Leishmania chagasi $(9,4 \%$ del total de casos de leihmaniasis) (4-6). El vector principal de L. chagasi es la especie Lutzomyia longipalpis. Por medio de análisis isoenzimáticos entre diferentes poblaciones, se ha demostrado que L. longipalpis de Colombia, Costa Rica y Brazil son tres especies bien diferenciadas no relacionadas entre sí; esto tiene importancia en la presentación clínica de la enfermedad (7).

La infección con $L$. chagasi está más frecuentemente asociada con la forma visceral de la enfermedad, pero produce formas cutáneas ulcerativas en centroamérica (Costa Rica y Honduras) (7); en Colombia se ha informado un caso de leishmaniasis cutánea por L. chagasi (8). Entre las posibles explicaciones para este fenómeno se mencionan: la

M.D., M.Sc. Dermatóloga. Docente, Centro Dermatológico Federico Lleras Acosta. Universidad Javeriana, Bogotá, Colombia

2 M.D., Ph. D. Dermatólogo. Investigador, Cutaneous Biology Research Center, Massachusetts General Hospital, Harvard Medical School, Charlestown, MA, USA. 
existencia de variantes de L. chagasi que difieren en la virulencia, la respuesta inmunológica del huésped y las diferencias entre las especies de L. longipalpis (7).

La picadura de Lutzomyia produce una mácula eritematosa, irregular, rodeada por un halo blanquecino; esta reacción se ha atribuido a un péptido que se ha aislado de las glándulas salivales del vector; fue caracterizado y clonado por Lerner y colaboradores en 1991, quienes lo llamaron maxadilán $(9,10)$.

El maxadilán es sintetizado como un prepropéptido de 63 aminoácidos el cual, mediante clivaje en el carbono terminal y amidación, queda convertido en un péptido de 61 aminoácidos. Contiene, además, cuatro residuos de cisteína que participan en la formación de puentes disulfuro entre las posiciones 1-5 y 14-51 (10). El maxadilán aumenta los niveles de AMP cíclico y se une a un receptor de membrana, miembro de la familia de los receptores acoplados a la proteína G (utilizan GDP). Los estudios iniciales demostraron una ligera homología entre la secuencia primaria del maxadilán y el péptido relacionado con el gen de la calcitonina (CGRP), por lo que se pensó que el maxadilán podría unirse a una subclase del receptor del CGRP. El CGRP es un neuropéptido presente en varias regiones anatómicas que incluyen los nervios cutáneos y el sistema nervioso central y que tiene, al igual que el maxadilán, actividad vasodilatadora e inmunomoduladora; pero, a pesar de estas similitudes, se demostró por estudios in vitro con anillos de pared aórtica que el maxadilán no es un agonista del receptor del CGRP (11).

Recientemente se encontró que el maxadilán es un agonista del receptor tipo I del péptido activante de la adenilciclasa pituitaria (PACAP) (12). Este péptido fue aislado del hipotálamo ovino y tiene una potente actividad en el estímulo de la producción del AMP cíclico en las células de la hipófisis anterior de ratas (13). Se postula que tendría actividad como neuromodulador o neurotransmisor en el control de la comunicación hipotálamo-hipofisiaria y en el sistema nervioso periférico en humanos; los receptores de PACAP se expresan también en algunos tejidos periféricos como los testículos, las glándulas suprarrenales y el intestino (14).

Hay dos formas funcionales de PACAP de acuerdo con el número de aminoácidos: una corta, llamada PACAP-27 y, una larga, PACAP38. Se han descrito tres receptores para el PACAP-38, dos de los cuales funcionan, además, como receptores del péptido intestinal vasoactivo (VIP); éstos se conocen como PACAP, tipo I, PACAP, tipo II (receptor tipo I, VIP) y PACAP, tipo III (receptor tipo II, VIP). EI receptor PACAP, tipo I, es el más específico porque la afinidad por este ligando es 1.000 veces mayor que la afinidad por el VIP (15). Aunque el maxadilán y el PACAP compiten por el mismo receptor e inducen la acumulación del AMP cíclico, no comparten secuencias homólogas y lo más interesante es que se derivan de especies no relacionadas (insecto y mamíferos, respectivamente).

El maxadilán es un potente vasodilatador. En la piel tiene no sólo efecto vasodilatador sino inmunomodulador. Después de cinco minutos de la inyección intradérmica de maxadilán, aparece una mácula eritematosa, brillante, circunscrita que persiste 48 horas; no se asocia con prurito, dolor ni efectos sistémicos; por el contrario, el eritema inducido por la histamina desaparece en menos de dos horas. El efecto persistente del maxadilán puede ser ocasionado por una alta afinidad de éste por su receptor. En experimentos in vitro con anillos de pared aórtica de conejo, se encontró que el maxadilán produce una relajación prolongada y aumento en los niveles de AMP cíclico y hace que la recontracción con adrenalina (vasoconstrictor) sea lenta; comparado con el neuropéptido CGRP, el maxadilán es 1.000 veces más potente en cuanto a su acción vasodilatadora (11).

El maxadilán tiene, además, una acción inhibitoria sobre la proliferación de células $T$ esplénicas murinas estimuladas con concanavalina $A$ y en la presentación de aloantígenos cuando se agrega a un cultivo mixto de linfocitos. Se ha observado que inhibe la hipersensibilidad retardada en el ratón (16). 
Se ha encontrado que el maxadilán se une con alta afinidad a receptores en la aorta y en el bazo de conejo y en el cerebro de diferentes especies. La unión en el bazo es coherente con la interacción del maxadilán con las células del sistema inmune y los estudios en cerebro de rata y humanos revelan una amplia distribución de los sitios de unión en el cerebro, por lo que no sorprende que comparta acciones con los neuropéptidos $(17,18)$.

Warburg y colaboradores han demostrado que la saliva de los vectores de Leishmania en focos de Colombia y Brazil, donde las Lutzomyia transmiten parásitos exclusivamente de compromiso visceral, tiene mayor actividad vasodilatadora que la saliva de los vectores de Costa Rica, en los cuales la menor actividad se debía a menores cantidades de maxadilán. Como la saliva de Lutzomyia longipalpis de Costa Rica tiene menor actividad vasodilatadora y la transmisión de L. chagasi se asocia con formas cutáneas de la enfermedad, ellos proponen que los promastigotes transmitidos por estos vectores infectarían principalmente a los macrófagos dérmicos y causarían una rápida proliferación local de los parásitos de $L$. chagasi. Cuando éstos son inyectados con la saliva que contiene maxadilán, la vasodilatación inducida por el péptido permitiría que un mayor número de monocitos circulantes infiltren el sitio de entrada a través de la vía sanguínea y linfática, facilitando su parasitismo y la precoz visceralización de la infección (19). En la figura 1 se resumen las actividades conocidas del maxadilán.

Como el maxadilán comparte el receptor con un péptido endógeno (PACAP), cuya distribución en la piel no es conocida aún, se diseñó un protocolo para tratar de detectar los sitios de unión del PACAP en la piel humana normal. Se utilizó la autorradiografía, técnica mediante la cual una sustancia marcada radiactivamente se pone en contacto con una muestra de piel y, utilizando una emulsión fotográfica, se obtiene una imagen que permite observar la distribución de la sustancia en estudio. Los resultados preliminares mostraron que el PACAP tiene sitios de unión en la epi- dermis y en la dermis. En la dermis, la mayor densidad de sitios de unión se observó en áreas de la papila dérmica y en los folículos pilosos; no hubo distribución alrededor de las glándulas sebáceas o sudoríparas (figura 2).

La importancia de la unión del PACAP a estas estructuras de la piel es incierta; es posible que el maxadilán ocupe receptores en los que endógenamente actúa el PACAP; el conocer estas interacciones nos permitirá avanzar en el estudio de los mecanismos de acción de los péptidos derivados de artrópodos, en la patogénesis de ciertas enfermedades como la leishmaniasis y su papel en la piel de los neuropéptidos en condiciones fisiológicas y patológicas. Se postula que el maxadilán por sus efectos de vasodilatación e inhibición de la respuesta inmune permitiría que los pro-

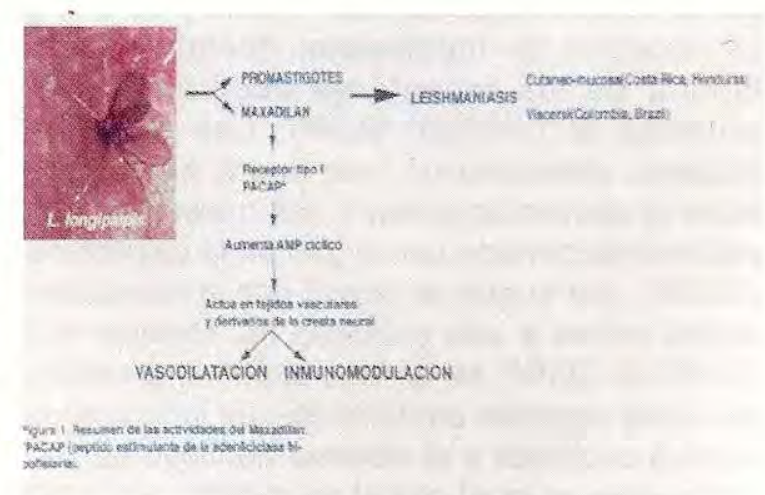

Figura 1. Resumen de las actividades del maxadilán.

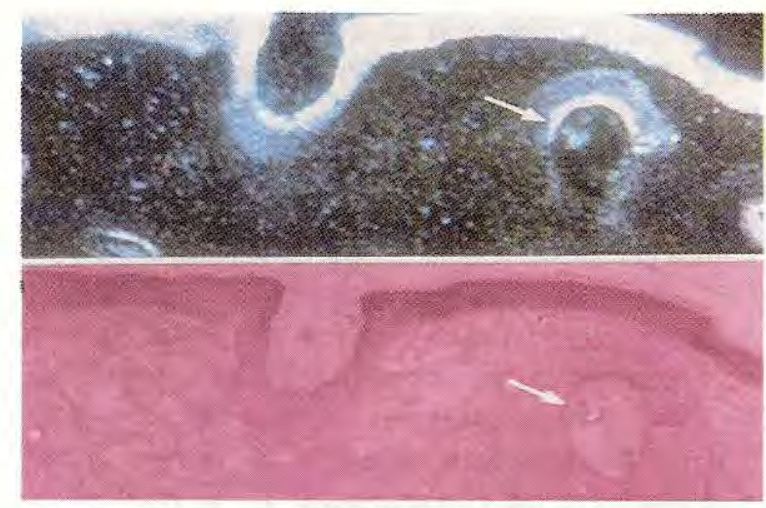

Figura 2. Distribución de I25-PACAP(PACAP marcado con yodo) en epidermis y folículos pilosos (flecha). A. Campo oscuro. B. Hematoxilina-eosina 20X. 
mastigotes de Leishmania se diseminen y se visceralize la enfermedad.

Los estudios que actualmente se llevan a cabo, indican que el maxadilán podría utilizarse como agonista o para la generación de un antagonista específico del receptor tipo I del PACAP (12) lo que permitirá estudiar la actividad de los neuropéptidos y de los péptidos exógenos en la piel y, así, contrarrestar o potenciar su acción, y plantear nuevas alternativas terapeúticas.

\section{Agradecimientos}

Esta publicación ha sido realizada con la colaboración financiera de Colciencias, entidad cuyo objetivo es impulsar el desarrollo científico y tecnológico de Colombia.

\section{Referencias}

1. Leishman WB. On the possibility of the occurrence of trypanosomiasis in India. BMJ 1903;1:252-4.

2. Grevelink S, Lerner EA. Leishmaniasis. J Am Acad Dermatol 1996;34:257-72.

3. Titus R, Ribeiro JM. Salivary gland lysates from the sandfly Lutzomyia longipalpis enhance Leishmania infectivity. Science 1988;239:1306-8.

4. Weigle KA, Saravia NG, de Dávalos M, Moreno LH, D'Alessandro A. Leishmania braziliensis from the $\mathrm{Pa}$ cific coast region of Colombia: foci of transmission, clini$\mathrm{cal}$ spectrum and isoenzime phenotypes. Am J Trop Med Hyg 1986;35:722-31.

5. Corredor A, Kreutzer RD, Tesh RB, Boshell J, Paláu MT, Cáceres E, et al. Distribution and etiology of leishmaniasis in Colombia. Am J Trop Med Hyg 1990; 42:206-14.

6. Corredor A, Gallego JF, Tesh RB, Morales A, Palau MT, Cáceres E, et al. Epidemiology of visceral leishmaniasis in Colombia. Am J Trop Med Hyg 1989;40:480-6.

7. Lanzaro GC, Ostrovska K, Herrero MV, Lawyer PG, Warburg A. Lutzomyia longipalpis is a species complex: genetic divergence and interspecific hybrid sterility among three populations. Am J Trop Med Hyg 1993; 48:839-47.
8. Hernández CA, Paláu MT, Corredor A, Nicholls RS, Cáceres E, Gualdron LE. Lesiones cutáneas causadas por Leishmania chagasi. Presentación de un caso. Resúmenes IV Congreso Latinoamericano de Medicina Tropical y IV Congreso Ecuatoriano de Medicina Tropical y Parasitología. Guayaquil, 1993.

9. Lerner EA, Ribeiro JM, Nelson JR, Lerner MR. Isolation of maxadilan, a potent vasodilator peptide from the salivary gland of the sandfly Lutzomyia longipalpis. $J$ Biol Chem 1991;266:11234-6.

10. Lerner EA, Shoemaker CB. Maxadilan: cloning and functional expression of the gene encoding this potent vasodilator peptide. J Biol Chem 1992;267:1062-6.

11. Grevelink S, Osborne J, Loscalzo J, Lerner EA. Vasorelaxant and second messenger effects effects of maxadilan. J Pharm Exp Ther 1995; 272: 33-37.

12. Moro O, Lerner EA. Maxadilan, the vasodilator peptide from sandflies is a specific PACAP type I receptor agonist. Sometido a publicación.

13. Hashimoto $\mathbf{H}$, Ishihara T, Shigemoto R, Mori K, Nagata S. Molecular cloning and tissue distribution of a receptor for pituitary adenilate cyclase-activating polypeptide. Neuron 1993;11:333-42.

14. Arimura A, Shioda S. Pituitary adenylate cyclase activating polypeptide (PACAP) and its receptors: neuroendocrine and endocrine interaction. Front Neuroendocrinol 1995; 16:53-88.

15. Rawlings S, Piuz I, Schlegel W, Bockaert J, Journot L. Differential expression of pituitary adenylate cyclaseactivating polypeptide/vasoactive intestinal polypeptide receptor subtypes in clonal pituitary somatotroph and gonadotrophs. Endocrinology 1995;136:2088-98.

16. Qureshi A, Lerner EA. Immunomodulatory properties of maxadilan, the vasodilator peptide from sandfly salivary gland extracts. Am J Trop Med Hyg (en prensa).

17. Moro O,Tsomides T, Tajima M, Lerner EA. Maxadilan binds to membrane fractions of brain tissue. Biochem Biophys Res Comm 1995;126:234-41.

18. Moro O, Tajima M, Lerner EA. Receptors for the vasodilator maxadilan are expressed on selected neurocrest and smooth muscle-derived cells. Insec Bioch Molec Biol (en prensa).

19. Warburg A, Saravia E, Lanzaro G, Titus R, Neva F. Saliva of Lutzomyia longipalpis sibling species differs in its composition and capacity to enhance leishmaniasis. Phil Trans R Soc Lond 1994;345:223-30. 